\title{
Synthesis and Characterization of ZnO-Ag Nanoparticles Supported on MCM-41 as Photocatalyst
}

\author{
EVA M. BARRERA-RENDÓN ${ }^{1,2}$, JAIME JIMÉNEZ-BECERRIL ${ }^{2 *}$ and \\ GENOVEVA GARCÍA-ROSALES 1 \\ 'Departamento de Estudios de Posgrado e Investigación, Instituto Tecnológico \\ de Toluca, Metepec, México. \\ 2Departamento de Química, Instituto Nacional de Investigaciones \\ Nucleares, Cd. De México, México. \\ *Corresponding author E-mail: jaime.jimenez@inin.gob.mx
}

http://dx.doi.org/10.13005/ojc/330212

(Received: October 13, 2016; Accepted: February 02, 2017)

\begin{abstract}
Development of photocatalyst is a key step for separation of photocatalyst to solution supported materials. $\mathrm{ZnO}-\mathrm{Ag} / \mathrm{MCM}-41$ nanoparticles synthetized by a wet process were studied as photocatalysts in the Congo red photodegradation, which is a water contaminant. Also were used prepared zinc oxide, commercial zinc oxide, silver doped zinc oxide, Mobil Catalytic Material No. 41, zinc oxide supported on MCM-41, and commercial zinc oxide supported on MCM-41. All systems were characterized by SEM, FTIR, XRD, and surface area by BET and tested in photocatalytic degradation of Congo red. It was found that the systems showed the crystalline phase wurtzita for $\mathrm{ZnO}$, and a main amorphous component for MCM-41, ZnO/MCM-41 and ZnOC/MCM-41. The materials had different particle size and morphology; however, predominantly spherical nanoparticles (less than $100 \mathrm{~nm}$ ) were found. For photocatalytic UV irradiation a maxima degradation of $30 \%$ for $120 \mathrm{~min}$ was reached with a $\mathrm{ZnO}-\mathrm{Ag}$ as catalyst.
\end{abstract}

Keywords: Nanoparticles; Photodegradation; Congo red; $\mathrm{ZnO}$ supported

\section{INTRODUCTION}

In textile industry, dyes are used as raw material, which generates 525,000 tons per month of waste water'; as example of dye used in the past is the Congo red, which was prohibited because of its toxicity, mutagenic and carcinogenic properties. Some alternative solutions to eliminate such pollutants are studied ${ }^{2}$. By nanotechnology synthesis it is possible to obtain new materials with specific properties, among them the photocatalytic activity is a viable option for the degradation of organic pollutants ${ }^{3}$. Photocatalysis belongs to AOP (Advanced Oxidation Processes) for destruction of chemical pollutants where hydroxyl radicals are produced to oxidize organic compounds. 
Photocatalysis is the activation of a photochemical reaction using ultraviolet light or visible light as chemical energy by the presence of a catalyst substrate ${ }^{4}$. Zinc oxide $(\mathrm{ZnO})$ is a photocatalyst reported in the literature, it has photocatalytic activity, strong oxidative capacity, and lower cost, which make it attractive solution for waste water treatment ${ }^{5}$. Besides, it has an open hexagonal close packed lattice where $\mathrm{Zn}$ atoms occupy half of the tetrahedral sites while all the octahedral sites are empty. Hence, there are sites available accommodating higher doping concentration limits in the host lattice ${ }^{6}$. The presence of Ag improves its photocatalytic properties ${ }^{7,8}$, by promoting interfacial electron-hole spacing ${ }^{9}$ and the Ag addition may trap photogenerated electrons ${ }^{10}$.

In studies with silver doped zinc oxide ( $\mathrm{ZnO}$ $\mathrm{Ag}$ ) nanoparticles, if the photocatalyst is synthesized in nanosize scale, its manipulation becomes difficult for the treatment of effluents ${ }^{11}$, and there are not experiments using Mobil Catalytic Material No. 41 (MCM-41) as support, however, it does with others. $\mathrm{Lu}^{12}$ prepared chitosan- $\mathrm{Ag} / \mathrm{ZnO}$ composite, and they found that supporting photocatalyst is an effective way to reduce the amount of nanoparticles; The use of only $\mathrm{ZnO} / \mathrm{Ag}$ nanoparticles has the disadvantage of release nanoparticles into the environment during the treatment process poses a health risk, so, nanoparticles typically must be supported on substrates such as clays such as bentonite ${ }^{13}$.

In this research is focused to support $\mathrm{ZnO}$ $\mathrm{Ag}$, for that, nanoparticles of $\mathrm{ZnO}-\mathrm{Ag} / \mathrm{MCM}-41, \mathrm{ZnO}$, commercial zinc oxide ( $\mathrm{ZnOC}$ ), ZnO-Ag, MCM-41, $\mathrm{ZnO} / \mathrm{MCM}-41$, ZnOC/MCM-41 were synthesized by wet method and were characterized and evaluated their photodegradation activity of Congo Red.

\section{Method \\ Materials}

Sigma Aldrich reagents of dihydrate zinc acetate, $\mathrm{AgNO}_{3}$, hydrogen peroxide $30 \%$, hexadecyltri-methylammonium bromide, ethylamine, tetra-methylammonium hydroxide, and tetraethylorthosilicate were used for synthesis.

\section{Synthesis of $\mathrm{ZnO}$ nanoparticles}

For synthesis of $\mathrm{ZnO}$ nanoparticles, were prepared $1.087 \mathrm{~g}$ of dihydrate zinc acetate on 150
$\mathrm{mL}$ of distilled water. Mixture of $15 \mathrm{~mL}$ of hydrogen peroxide $30 \%$ was added with constant agitation, and maintained at reflux for 2 hour. Particles formed were recovered by centrifugation at $6000 \mathrm{rpm}$ and dried at $80^{\circ} \mathrm{C}$. Then the material was heat treated at $300^{\circ} \mathrm{C}$ for 2 hours.

\section{Synthesis of ZnO-Ag nanoparticles}

To obtain $\mathrm{ZnO}-\mathrm{Ag}$ nanoparticles, $1.3 \mathrm{~g}$ of $\mathrm{AgNO}_{3}$ on $7.5 \mathrm{~mL}$ of distilled water in constant agitation was added the $\mathrm{ZnO}$ nanoparticles during $1 \mathrm{~h}$. Then, they were dried at $80^{\circ} \mathrm{C}$ of temperature for $6 \mathrm{~h}$. $\mathrm{ZnO}-\mathrm{Ag}$ nanoparticles were heat treated at $300^{\circ} \mathrm{C}$ for 2 hours.

\section{Synthesis of MCM-41}

For the preparation of MCM-41 was used the method reported by $\mathrm{Yin}^{14} .2 .43 \mathrm{~g}$ of hexadecyltrimethylammonium bromide was dissolved in $67 \mathrm{~mL}$ of water. A solution of $1.11 \mathrm{~mL}$ of ethylamine and $6 \mathrm{~mL}$ of tetramethylammonium hydroxide was added. Then $8 \mathrm{~mL}$ tetraethylorthosilicate was added. The solution was aged for 24 hours. Particles formed were recovered by centrifugation at $5000 \mathrm{rpm}$ and then dried at $80^{\circ} \mathrm{C}$ for 24 hours. Finally, the material was calcined for $5 \mathrm{~h}$ at $550^{\circ} \mathrm{C}$.

\section{Synthesis of ZnO-Ag/MCM-41}

For obtain the material of $\mathrm{ZnO}-\mathrm{Ag} / \mathrm{MCM}-41$, in $5 \mathrm{~mL}$ of distilled water were suspended $0.04 \mathrm{~g}$ of ZnO-Ag nanoparticles, $3 \mathrm{~g}$ of MCM-41 were added with agitation during 1 hour.

For $\mathrm{ZnO} / \mathrm{MCM}-41$ and $\mathrm{ZnOC} / \mathrm{MCM}-41$ systems, syntheses were conducted like in $\mathrm{ZnO}-\mathrm{Ag} /$ MCM-41 synthesis.

\section{Sample characterization}

The morphology was examined using a scanning electron microscope (SEM, JEOL JSM$6610 \mathrm{LV})$. The structural and phase identification of samples were characterized by a powder X-ray diffraction (XRD, Bruker D8 Discover). The functional groups identification of samples was characterized by IR spectrometer with Fourier transform (FTIR, Magna-IR Spectrometer 550). The absorbance of Congo red solution was measured by a UV-Vis spectrophotometer (UV-Vis Lambda 25 Perkin Elmer). 


\section{Photocatalytic activity test}

Congo red (CR) dye was used as a dye model to evaluate a photocatalytic degradation of samples response to UV irradiation at room temperature. The experiments were carried out as follows: $100 \mathrm{mg}$ of sample were dispersed into 100 $\mathrm{mL}$ of a $20 \mathrm{mg} / \mathrm{L}$ CR solution in a glass beaker. Prior to irradiation, the mixtures were stirred in the dark for 1 hour to ensure equilibrium of CR adsorption and desorption, then the samples had an irradiation with an UV lamp (black light at $\lambda=354 \mathrm{~nm}, 8 \mathrm{~W}$ ), at a distance of $10 \mathrm{~cm}$ from a glass beaker. At given intervals $(1 \mathrm{~h}), 5 \mathrm{~mL}$ samples of the mixtures were collected and subsequently filtered to separate solid and solution. Then, remained CR was determined at $497 \mathrm{~nm}$ in a Perkin Elmer, Lambda 35 UV/Vis spectrophotometer.

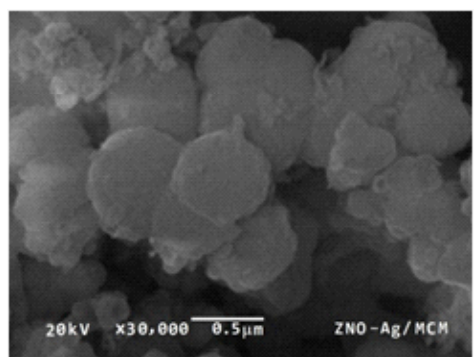

a

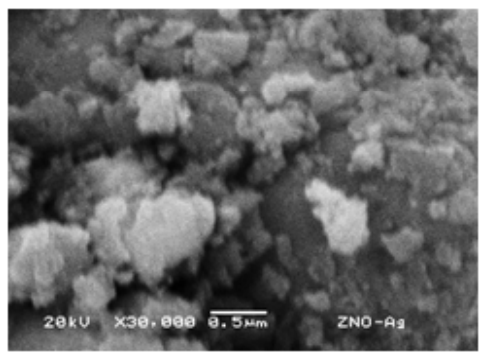

d

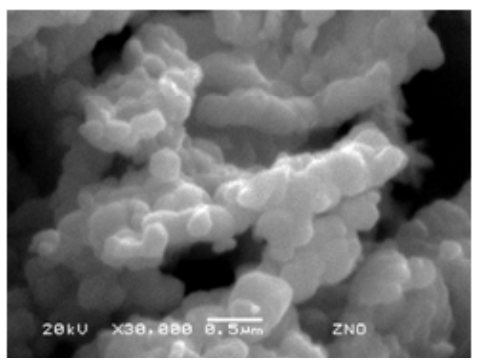

b

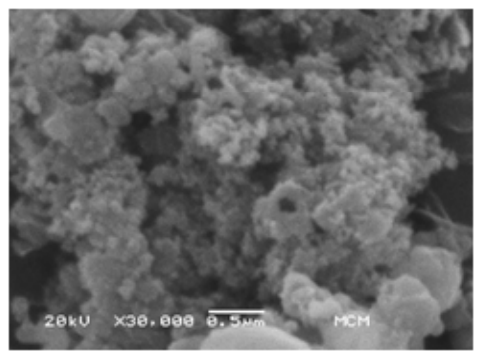

e

f
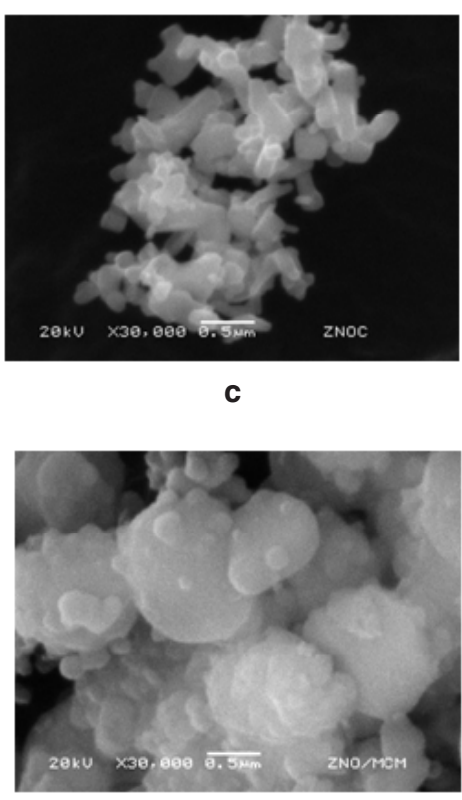

C

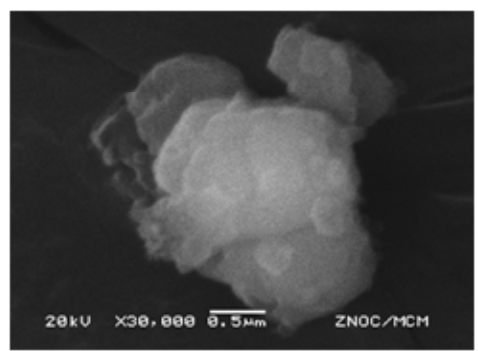

g

Fig. 1: SEM of a) ZnO-Ag/MCM-41, b) ZnO, c) ZnOC, d) ZnO-Ag, e) MCM-41, f) ZnO/MCM-41, g) $\mathrm{ZnOC/MCM-41}$ 
grew independently when loaded with $\mathrm{Ag}$, this might reduce a surface energy did not occur ${ }^{15}$. The MCM-41 be due to a larger particle size having a lower surface particles are spheres with different sizes and when energy, so an agglomeration of particles that would loading with $\mathrm{ZnO}, \mathrm{ZnOC}$ (Fig. 1c) and $\mathrm{ZnO}-\mathrm{Ag}$ it
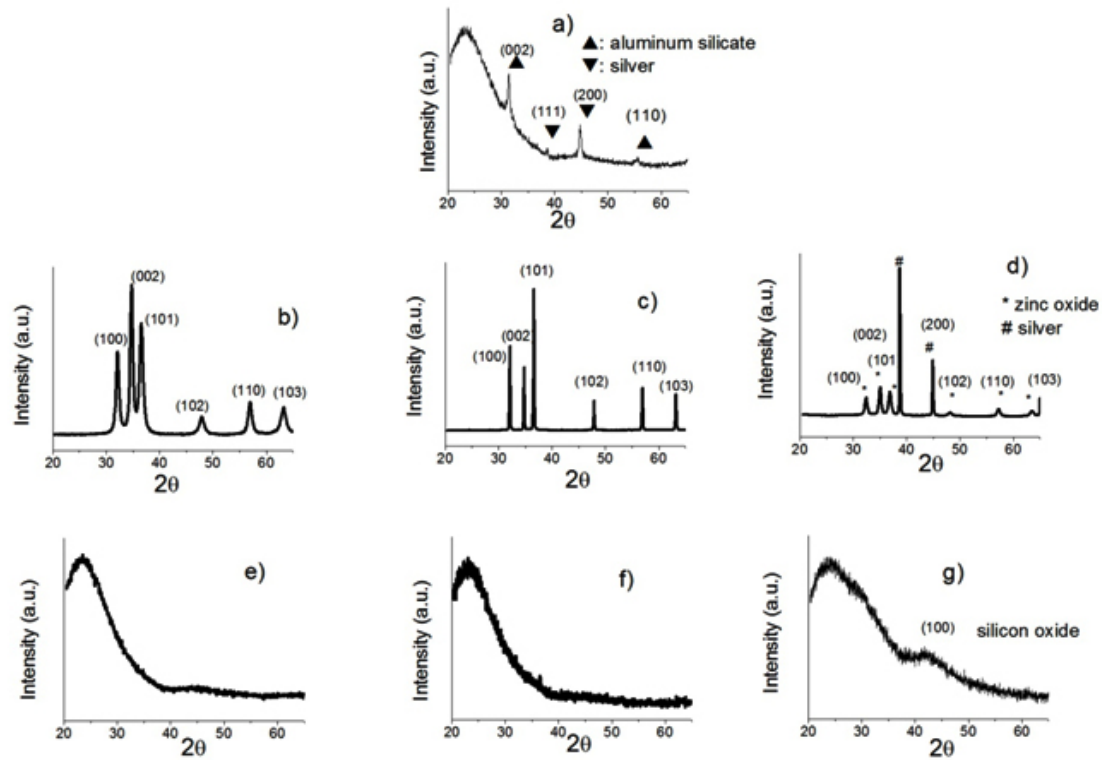

Fig. 2: XRD of a) ZnO-Ag/MCM-41, b) ZnO, c) ZnOC, d) ZnO-Ag, e) MCM-41, f) ZnO/MCM-41, g) $\mathrm{ZnOC/MCM}-41$
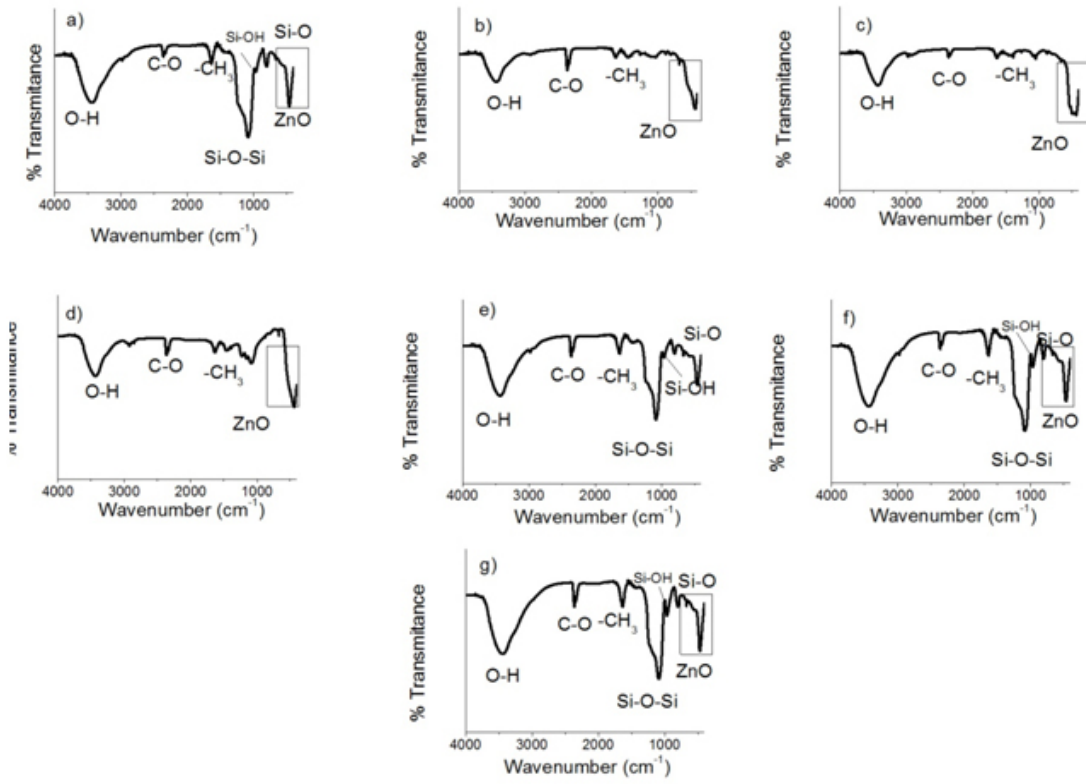

Fig. 3: FT-IR of a) ZnO-Ag/MCM-41, b) ZnO, c) ZnOC, d) ZnO-Ag, e) MCM-41, f) ZnO/MCM-41, g) ZnOC/MCM-41 
observed that the size higher than without loading and the morphology are much defined (Table 1). In other hand, elemental analysis results showed the elements in each system ( $\mathrm{Zn}, \mathrm{O}, \mathrm{Ag}, \mathrm{Si}, \mathrm{Al}, \mathrm{C})$.

\section{Phase identification}

The XRD patterns of $\mathrm{ZnO}-\mathrm{Ag} / \mathrm{MCM}-41$, $\mathrm{ZnO}, \mathrm{ZnOC}, \mathrm{ZnO}-\mathrm{Ag}, \mathrm{MCM}-41, \mathrm{ZnO} / \mathrm{MCM}-41$, ZnOC/MCM-41 particles are presented in Fig. 2. For $\mathrm{ZnO}-\mathrm{Ag} / \mathrm{MCM}-41$, Fig. 2a) shows presence of aluminum silicate (JCPDS No. 00-052-0142), and metallic Ag (JCPDS No. 00-004-0783). Also it is observed presence of amorphous material due to $\mathrm{MCM}-41$. For $\mathrm{ZnO}$ Fig. 2b) and $\mathrm{ZnO}$ commercial Fig. 2c), the main patterns are hexagonal wurtzite (JCPDS No. 00-036-1461); the different intensities prove the small size of the particles. The XRD patterns in Fig. 2d) also exhibited a small peak

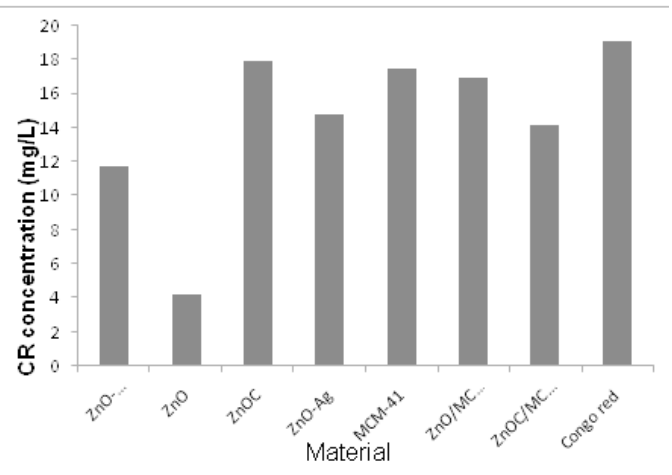

Fig. 4: Adsorption of CR at [20 mg/L] with irradiation time for $\mathbf{0} \mathrm{min}$ of metallic $\mathrm{Ag}$ at 38.8 and $44.92 \theta$ in its cubic and wurtzite phase; this indicate that $\mathrm{ZnO}-\mathrm{Ag}$ nanoparticles were completely formed ${ }^{16,17}$. Fig. $2 \mathrm{e}, 2 \mathrm{f}$ and $2 \mathrm{~g}$ ) show amorphous material of silicon oxide, component of MCM-41, besides the difference between $\mathrm{ZnO} / \mathrm{MCM}-41$ and $\mathrm{ZnOC} / \mathrm{MCM}$ 41 is the silicon oxide peak in 42.412 , caused for $\mathrm{ZnOC}$.

\section{IR characterization}

In Fig. 3 are presented the FT-IR spectra of the $\mathrm{ZnO}-\mathrm{Ag} / \mathrm{MCM}-41, \mathrm{ZnO}, \mathrm{ZnOC}, \mathrm{ZnO}-\mathrm{Ag}$, MCM-41, ZnO/MCM-41, ZnOC/MCM-41. The main infrared absorption peaks are located in the middle and lower frequency zones. Hydroxyl groups and water molecules are confirmed by the broad bands detected at high frequency at around 3432 $\mathrm{cm}^{-1}$, where the broadening of this band is due to $\mathrm{O}-\mathrm{H}$ bond. The peak at $1612 \mathrm{~cm}^{-1}$ belongs to $-\mathrm{CH}_{3}$ vibrations from the surfactant of zinc acetate and it becomes remarkable after thermal treatment ${ }^{18}$. The band from 1260 to $1006 \mathrm{~cm}^{-1}$ represents $\mathrm{Si}$ O-Si functional group; the peaks in $988 \mathrm{~cm}^{-1}$ and 760 belong to $\mathrm{Si}-\mathrm{OH}$ and $\mathrm{Si}-\mathrm{O}$ vibrations from the mesoporous MCM-41 ${ }^{19}$. IR spectra of $\mathrm{ZnO}$ show that absorption peaks in the range $600-400 \mathrm{~cm}^{-1}$, indicating the formation of $\mathrm{ZnO}$ nanospheres assembled microspheres ${ }^{18,20,21}$.

\section{Surface area analysis}

BET surface area analysis has been done by $\mathrm{N}_{2}$ physical adsorption on the particle surface and the obtained data were summarized in the Table 1. The largest surface area is presented for sample

Table 1: Elemental analysis EDX of ZnO, ZnOC, ZnO-Ag, MCM-41, ZnO/MCM-41, $\mathrm{ZnOC/MCM-41and} \mathrm{ZnO-Ag/MCM-41}$

\begin{tabular}{lcccccccc}
\hline Material & Size $(\mathbf{n m})$ & $\begin{array}{c}\text { Surface } \\
\text { area }\left(\mathbf{m}^{2} \mathbf{g}^{-1}\right)\end{array}$ & $\mathbf{Z n}$ & $\mathbf{0}$ & $\begin{array}{c}\text { Ag } \\
\text { Ag }\end{array}$ & $\begin{array}{c}\text { atomic } \\
\text { Si }\end{array}$ & Al & C \\
ZnO & 64 & 8.6 & 40.6 & 59.4 & - & - & - & - \\
ZnOC & 141 & 5.2 & 52.7 & 47.3 & - & - & - & - \\
ZnO-Ag & 67 & 5.1 & 34.3 & 59.0 & 6.7 & - & - & - \\
MCM-41 & 33 & 1120.0 & - & 23.5 & - & 18.5 & 27.8 & 30.2 \\
ZnO/MCM-41 & 122 & 1030.0 & 0.1 & 62.6 & - & 17.9 & - & 19.4 \\
ZnOC/MCM-41 & 38 & 1090.0 & 0.1 & 65.2 & - & 14.4 & - & 20.3 \\
ZnO-Ag/MCM-41 & 202 & 1040.0 & 0.1 & 70.6 & 0.3 & 28.8 & 0.2 & - \\
\hline
\end{tabular}




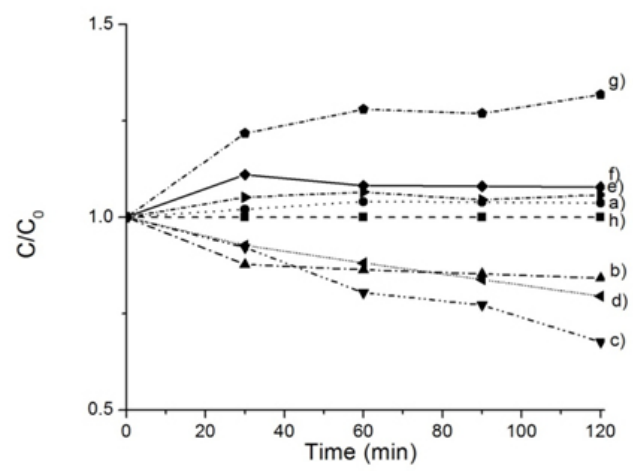

Fig. 5: Photocatalysis test of CR degradation at [20 mg/L] with irradiation time for $120 \mathrm{~min}$ of: a) ZnO-Ag/MCM-41, b) ZnO, c) ZnOC, d) ZnO-Ag, e) MCM-41, f) ZnO/MCM-41, g) ZnOC/MCM-41 as catalysts and $\mathrm{h}$ ) without catalyst

MCM-41 $\left(1120 \mathrm{~m}^{2} \cdot \mathrm{g}^{-1}\right)$, similar to $\mathrm{López}^{22}$, and the smallest surface area belongs to $\mathrm{ZnO}-\mathrm{Ag}(5.1$ $\left.\mathrm{m}^{2} \cdot \mathrm{g}^{-1}\right)$. This fact confirms that the metal presence has influence on the surface area, which was closely related to the catalytic activity ${ }^{23}$. Specifically, the silver presence implied a smaller surface area, which could be caused from the formation of larger $\mathrm{ZnO}$ crystals with high crystallinity ${ }^{24,25}$.

\section{Photocatalytic activity}

Fig. 4 shows the adsorption of $\mathrm{CR}$ in used materials; the results indicate that $\mathrm{ZnO}$ is the material which possess a bigger adsorption than $\mathrm{ZnO}-\mathrm{Ag} / \mathrm{MCM}-41$, this result coincide with the surface area (8.6 and $1040 \mathrm{~m}^{2} \mathrm{~g}^{-1}$, respectively); if the area is smaller, the contact area with the pollutant is bigger. $\mathrm{ZnOC}$ has the smaller adsorption of all materials, this is because it is not a nanoparticle $(141 \mathrm{~nm})$ and it does not have spherical form.

The photocatalysis of $\mathrm{ZnO}-\mathrm{Ag} / \mathrm{MCM}-41$, $\mathrm{ZnO}, \mathrm{ZnOC}, \mathrm{ZnO}-\mathrm{Ag}, \mathrm{MCM}-41$, ZnO/MCM-41, ZnOC/MCM-41 was assessed by the photodegradation of CR with UV light irradiation. Fig. 5 shows the $\mathrm{CR}$ removal efficiency as a function of irradiation time using different solid catalysts. The blank test without catalysts testified that the photoinduced selfdecomposition of CR was negligible.

The degradation efficiency of single component $\mathrm{ZnO}$ sample was only $16 \%$ with 2 hours of irradiation like in the Fig. 5b). In the Fig. 5d) the as prepared $\mathrm{ZnO} / \mathrm{Ag}$ improves photocatalytic activity at $20 \%$ of CR remotion from the solution after 2 hours irradiation. The enhanced photocatalytic activity of the $\mathrm{ZnO}-\mathrm{Ag}$ particles can be interpreted firstly, the coupling of silver with $\mathrm{ZnO}$ supports created numerous high-specific-surface interphase boundaries that had an important influence on their physical properties ${ }^{26}$. Besides, the synthesis of $\mathrm{ZnO}-\mathrm{Ag}$ induced the strong electronic coupling between $\mathrm{ZnO}$ and $\mathrm{Ag}$, inhibiting the photogenerated electron-hole recombination and greatly prolonging the life time of charge carriers ${ }^{10}$. In other hand, the mesoporous MCM-41 in Fig. 5e), only adsorbs the $\mathrm{CR}$ and when is loaded with $\mathrm{ZnO}, \mathrm{ZnOC}$ and $\mathrm{ZnO}-\mathrm{Ag}$ (Fig. 5a, 5f, 5g), desorbs from 3\% to $30 \%$.

The observed photodesorption in MCM41, $\mathrm{ZnO} / \mathrm{MCM}-41$ and $\mathrm{ZnOC} / \mathrm{MCM}-41$ materials is because there are some phenomena on the surface of materials. The photodesorption occurred during light irradiation the adsorbed oxygen on $\mathrm{ZnO}$ is pumped away from the surface and oxygen from the ambient environment is re-adsorbed; the presence of carbon favors chemisorption of oxygen onto the surface and an electron is capture from the conduction band to form $\mathrm{CO}_{2}^{-}$, the ion may be neutralized by photohole under UV illumination ${ }^{27}$. Then, conductivity and photocatalytic efficiency decrease.

\section{CONCLUSIONS}

It was successfully prepared $\mathrm{ZnO}-\mathrm{Ag}$ nanoparticles supported on MCM-41 synthesized wet process. The main morphology of samples is spherical. The synthesized $\mathrm{ZnO}-\mathrm{Ag}$ material exhibited excellent CR photocatalytic degradation after UV irradiation for 120 minutes, which could be a promising photocatalyst in removing organic pollutants from waste water. The $\mathrm{ZnO}-\mathrm{Ag} / \mathrm{MCM}$ 41 material has a desorption behavior, caused by surface phenomena, mainly oxygen adsorptiondesorption during UV irradiation.

\section{ACKNOWLEDGEMENT}

The authors thank to CONACYT for scholarship No. 663749, to ININ (project No. CB504) and InstitutoTecnológico de Toluca for support (project No. DGEST 5894.16-P). 


\section{REFERENCES}

1 INEGI (Instituto Nacional de Estadística Geográfica e Informática)2003, Available at: http://www3.inegi.org.mx/sistemas/biblioteca/ ficha.aspx?upc=702825000039 Accesedon 26 March 2015.

Dafare, S.;Deshpande, P.S.; Bhavsar, R.S.Indian J. Chem. Techn.2013,20,406-410 Shemer, H.; Sharpless, C.M.; Linden, K.G.Water Air Soil Poll.2005, 168,145-155

Ohama, Y.; Van Gemert, D.Application of titanium dioxide photocatalysis to construction materials, 1st edn. Springer, USA, 2011, 1. Saoud, K.; Alsoubaihi, R.; Bensalah, N.; Bora, T.; Bertino, M.; Dutta, J.Mater. Res. Bull.2015,63,134-140 Sahu, R.K.; Ganguly, K.; Mishra, T.; Mishra, M.; Ningthoujam, R.S.; Roy, S.K.; Pathak, L.C.; J. Colloid Interf. Sci.2012,366,8-15

7 Zhao, Z.; Wang, M.; Liu, T.Mater. Lett.2015, 158,274-277

8 Chen, P.; Gu, L.; Xue, X.; Song, Y.; Zhu, L.; Cao, X.Mater. Chem. Phys.2010, 122,41-48 Bechambi, O.; Chalbi, M.; Najjar, W.; Sayad, S.Appl. Surf. Sci.2015,347,414-420 Xie, W.; Li, Y.; Sun, W.; Huang, J.; Xie, H.; Zhao, X.J. Photoch. Photobio A.2010,216,149-155 Huang, H.; Wang, H.P.; Chang, J.; Wei, Y.J. Electron Spectrosc.2007,156-158,357-360 Lu, Z.; Gao, J.; He, Q.; Wu, J.; Liang, D.; Yang, H.; Chen, R.Carbohyd. Polym.2016, doi:10.1016/j.carbpol.2016.09.051
Momba, M.N.B.Appl. Clay. Sci.2015, 114,330339

Yin, A.; Wen, C.; Dai, W.; Kangnian, F.Appl. Catal. B-Environ.2011,108-109,90-99

15 Klubnuan, S.; Amornpitoksuk, P.; Suwanboon, S.Mat. Sci. Semicon. Proc.2015,39,515-520

16 Wang, L.; Hou, X.; Li, F.; He, G.; Li, L.Mater. Lett.2015, 161,368-371

17 Hou, X.Mater. Lett.2015, 139,201-204

18 Reddy, M.M.; Reddy, G.R.; Chennakesavulu, K.; Sundaravadivel, E.; Prasath, S.S.; Rabel, A.M.; Sreeramulu, J.J. Porous Mater.2016, doi:10.1007/s10934-016-0247-3

19 Kiomarsipour, N.; Razavi, R.S.; Ghani, K.Dyes Pigments.2013,96,403-406

20 Wang, Y.; Zhou, G.; Guo, J.; Liu, T.Ceram. Int.2016,42, 2467-12474

21 Bera, S.; Khan, H.; Biswas, I.; Jana, S.Appl. Surf. Sci.2016,383,165-176

22 López, L. P.; Van Eck, E.R.H.; Melián-Cabrera, I.Micropor. Mesopor. Mat.2016,220,88-98

23 Li, D.; Haneda, H.Chemosphere.2003,51,129137

24 Yu, C.; Yang, K.; Xie, Y.; Fan, Q.; Yu, J.C.; Shu, Q.Nanoscale.2013,5,2142-2151

25 Muñoz-Fernandez, L.; Sierra-Fernandez, A.; Miloševiæ, O.; Rabanal, M.E.Adv. PowderTechnol.2016,27,983-993

26 Tietze, T.;Audehm, P.; Chen, Y.C.; Schütz, G.; Straumal, B.B.; Protasova, S.G.Sci. Rep.2015,5,8871

27 Zhang, D.H.Mater. Chem. Phys.1996,45,248252 